\title{
Distilling the essence of breathlessness: the first vital symptom
}

\author{
David C. Currow ${ }^{1,2,3}$ and Miriam J. Johnson ${ }^{4}$
}

Affiliations: ${ }^{1}$ Flinders University, Adelaide, Australia. ${ }^{2}$ Dartmouth-Hitchcock Medical Center, Lebanon, NH, USA. ${ }^{3}$ Geisel Medical School, Dartmouth College, Hanover, NH, USA. ${ }^{4}$ Hull York Medical School, Hull, UK.

Correspondence: David C. Currow, Flinders University, Palliative and Supportive Services, Daws Road, Daw Park, Adelaide, South Australia, Australia. E-mail: David.Currowahealth.sa.gov.au

@ERSpublications

Assessing and adequately treating refractory breathlessness is an explicit responsibility of every clinician http://ow.ly/LolmT

A physician is obligated to consider more than a diseased organ, more even than the whole man - he must view the man in his world

Harvey Williams Cushing

We have all heard the same words thousands of times. The consultation seems so routine, and so very predictable.

"How are you doing?"

"My breathing hasn't changed."

"It's good you haven't been in hospital for a while."

"I'm still quite breathless."

"Do you need a prescription for any of your medications?" ... and any opportunity to explore this man's breathlessness has passed yet again.

What the clinician is actually thinking during this encounter was: "I don't know why this man comes to see me every 3 months. I never change anything. I've optimised his puffers. Of course he's breathless - he has a forced expiratory volume in $1 \mathrm{~s}$ of $34 \%$. And after all, if his breathing is really distressing, he would tell me about it" $[1,2]$.

Our patients don't expect miracles, but they do expect support, real support. Rightly, they expect a clinician who is prepared to ask them how they are functioning on a day-to-day basis, what it is like to be this breathless and what would most make a difference. Most importantly, most of our patients are already too wise to expect that we can actually fix the breathlessness of advanced chronic obstructive pulmonary disease or interstitial lung disease, but there are things that we can do to support them without feeling the pressure to pretend we can make everything right. The very act of acknowledging the presence and impact of breathlessness is, in itself, a therapeutic intervention. It validates the experience of the person with breathlessness and gives explicit permission to talk about the effect on his/her life. The benefits of genuine empathy in the clinical encounter should not be underestimated.

For this patient, breathlessness is not merely a fact in a clinical history. It is a lived experience that is constant, worsening over time and, on occasion, overwhelmingly frightening [3]. Just because you and I as clinicians think that this person's breathlessness is "only to be expected", this does not justify turning a blind eye to this person's primary source of suffering. Just because it is inevitable that a person with progressive respiratory disease will get more breathless, this does not justify simply writing a repeat prescription rather than exploring the person's symptoms. Just because we may have little to offer to change the course of the underlying condition, it does not mean that we have little or nothing to offer the

Received: Feb 222015 | Accepted after revision: April 052015

Conflict of interest: Disclosures can be found alongside the online version of this article at erj.ersjournals.com

Copyright OERS 2015 
person. Above all else, we have a therapeutic relationship that allows us to help this person in ways no other human being can do.

To borrow from Cushing, what does this man with chronic progressive lung disease face in his world?

First, such chronic breathlessness, refractory to treatment for the causative disease(s), reflects for many people a shrinking social world [4]. Breathlessness prevents the mobility that most of us take for granted. Hence, people describe dying a social death, long before they die a physical death. Further, friends and relatives simply stop visiting as there is less and less to discuss as someone's world shrinks.

Rates of depression are higher in people with end-stage cardiorespiratory diseases than in the population as a whole [5]. Progressive losses resulting from symptoms that restrict basic activities of independent daily living (bathing, dressing, cooking) are difficult to cope with and create lasting sadness. The emotional impact may be further complicated for many by self-blame if, through lifestyle choices, they may feel that they have contributed to their current state and experience stigma (real or perceived) by family, friends and health professionals.

Existentially, breathlessness is a constant reminder of impending mortality. Most of us want to die in our sleep with no knowledge of the event. Not only do patients with chronic, progressive lung disease know of their impending death months, years or decades ahead of the day [6], they fear how they will die, with the fear of suffocation always somewhere in their minds. This is as frightening as life can be.

Physically, there is a cycle of decreasing ability and associated deconditioning, the latter ultimately worsening the breathlessness further, and chronic progressive, refractory breathlessness becomes the common pathway of so many disease states, made worse by the consequent poor mobility. This vicious cycle of deconditioning weakens the very muscles needed to breathe.

Breathlessness is a complex, debilitating and multidimensional sensation [7] but, to date, most of us rely on a unidimensional question in daily clinical practice ("How is your breathlessness?"), even though we know that breathlessness is multifaceted. Despite the apparently open-ended nature of the words used, in practice, even as a screening question it almost always blocks the person's ability to tell us about their breathlessness.

BANZETT et al. [8] are to be commended for the decades of work that has culminated in the publication in this issue of the European Respiratory Journal of a new and truly comprehensive tool for the evaluation of all of the facets of breathlessness in daily clinical practice and in research. The rigour of its development and subsequent testing are evidence of the commitment to ensure the complexity of the experience of living as a person with chronic refractory breathlessness is captured in all of the domains of life that it affects.

The medical novelist A.J. Cronin spoke in a radio interview of the medical profession's "unscientific stubbornness". Given the evidence-based interventions shown to safely reduce breathlessness that have emerged in the last 20 years [9], are we as clinicians doing what Cronin suggested of his colleagues decades ago? Are we unscientifically and stubbornly refusing to evaluate people's breathlessness using rigorously developed, well validated tools and respond to the evidence that we can reduce the experience of breathlessness as a result of the clinical evaluation?

As clinicians, we have a responsibility to address and manage breathlessness as more than a clinical marker of worsening lung disease. Given the evidence for interventions that improve this symptom, this is now a fundamental human right for people around the world [10]. To reduce breathlessness to a unidimensional clinical sign like peak expiratory flow or respiratory rate diminishes the person who lives with its debilitating effects and the fear that it engenders.

The explicit responsibility of doctors (and other health professionals) is to solicit and "respond to [patients'] concerns and preferences" [11]. Joint patient/doctor decision making to optimise individually tailored management is a conversation informed by the benefits and harms of every one of the available choices. This requires up-to-date knowledge as new evidence emerges, and the skills to communicate these choices in ways understood by the patient. Merely publishing work, even of the importance of the work of BANZETT et al. [8], will be insufficient to implement change in practice [12]. Such an approach must be modelled by senior clinicians; junior clinicians will then more readily follow and together they will teach the next generation of health professionals. Around the world, pain has started to shift from being an expected consequence of disease processes to something that can be effectively palliated for most people. Pain has risen to the status of a "vital sign". Given its devastatingly accurate contribution to prognosis [7], breathlessness is surely the most vital symptom and needs to be part of every clinical assessment, including assessment of its presence and impact on this person's life. Furthermore, realising that an affective component not only exists, but may be more responsive to evidence-based therapies, such as morphine, puts an onus on clinicians to actively seek and treat this disabling symptom [13]. Much work 
still needs to be done to fully understand the central mechanisms that modulate the lived experience of breathlessness, and both laboratory studies on healthy volunteers and innovative ways of working with people experiencing breathlessness to further elucidate the mechanisms and, from there, refine our interventions are required [14].

As clinicians and researchers, if we are committed to evidence-based care, the first step is to routinely measure the breathlessness from which our patients suffer and use the findings as the basis for a compassionate and evidence-based response. Treating breathlessness is no longer something that is an option: it is our duty as clinicians to systematically diminish the suffering that chronic refractory breathlessness causes for millions of people around the world. Patients have the right to expect good symptom control, even in the face of progressive disease. BANZETT et al. [8] have made the systematic evaluation of breathlessness a great deal easier and more comprehensive. Moreover, the Multidimensional Dyspnea Profile provides clinicians with a tool to potentially facilitate ongoing monitoring of breathlessness management. The common cry of clinicians is that they have no time to assess each of the domains that make up the complex sensation of breathlessness. If the potential of this user-friendly, multidimensional tool, administered in only a few minutes, is realised in clinical practice, then this cry will be silenced. Our opportunity is to introduce this assessment into our clinical practice and reduce our therapeutic nihilism in the face of such a primal symptom: being unable to breathe.

\section{References}

1 Hayes AW, Philip J, Spruyt OW. Patient reporting and doctor recognition of dyspnoea in a comprehensive cancer centre. Intern Med J 2006; 36: 381-384.

2 Homsi J, Walsh D, Rivera N, et al. Symptom evaluation in palliative medicine: patient report vs systematic assessment. Support Care Cancer 2006; 14: 444-453.

3 Gysels M, Bausewein C, Higginson IJ. Experiences of breathlessness: a systematic review of the qualitative literature. Palliat Support Care 2007; 5: 281-302.

4 Gysels M, Higginson IJ. The experience of breathlessness: the social course of chronic obstructive pulmonary disease. J Pain Symptom Manage 2010; 39: 555-563.

5 Yohannes AM, Willgoss TG, Baldwin RC, et al. Depression and anxiety in chronic heart failure and chronic obstructive pulmonary disease: prevalence, relevance, clinical implications and management principles. Int $J$ Geriatr Psychiatry 2010; 25: 1209-1221.

6 Johnson MJ, Bowden JA, Abernethy AP, et al. To what causes do people attribute their chronic breathlessness? A population survey. J Palliat Med 2012; 15: 744-750.

7 Laviolette L, Laveneziana P. Dyspnoea: a multidimensional and multidisciplinary approach. Eur Respir J 2014; 43: $1750-1762$.

8 Banzett RB, O’Donnell CR, Guilfoyle TE, et al. Multidimensional Dyspnea Profile: an instrument for clinical and laboratory research. Eur Respir J 2015; 45: 1681-1691.

9 Parshall MB, Schwartzstein RM, Adams L, et al. An official American Thoracic Society statement: update on the mechanisms, assessment, and management of dyspnea. Am J Respir Crit Care Med 2012; 185: 435-452.

10 Currow DC, Abernethy AP, Ko DN. The active identification and management of chronic refractory breathlessness is a human right. Thorax 2014; 69: 393-394.

11 General Medical Council. Good Medical Practice: Working with Doctors, Working for Patients. The duties of a doctor registered with the General Medical Council. Manchester, General Medical Council, 2014.

12 O'Brien MA, Rogers S, Jamtvedt G, et al. Educational outreach visits: effects on professional practice and health care outcomes. Cochrane Database Syst Rev 2007; 4: CD000409.

13 Banzett RB, Adams L, O'Donnell CR, et al. Using laboratory models to test treatment: morphine reduces dyspnea and hypercapnic ventilatory response. Am J Respir Crit Care Med 2011; 184: 920-927.

14 Johnson M, Simpson M, Millman R, et al. Magnetoencephalography as a neuro-imaging method in chronic dyspnoea: a feasibility study. Eur Respir J 2014; 44: Suppl. 58, P670. 